\title{
Canadian Forces gives CMA top honour
}

$\mathrm{T}$ he Canadian Armed Forces awarded its highest civilian honour to the Canadian Medical Association (CMA) during the organization's annual meeting in Ottawa Aug. 19.

Outgoing CMA President Dr. Louis Hugo Francescutti accepted on behalf of the organization the Canadian Forces Medallion for Distinguished Service from Chief of Defence Staff Gen. Tom Lawson.

"Each of you present today has chosen a career that is characterized by altruistic devotion and passion for life," Lawson told conference attendees. "Your leadership and exceptional devotion represent an important contribution to our country and others abroad."

The award recognizes "service of rare and exceptionally high standard which accrues benefit to the Canadian Armed Forces as a whole," said Lawson, and represents the highest honour the military can bestow on a civilian organization or individual.

Lawson lauded CMA's history of "considerable support for all Canadian Forces," from lobbying for the creation of the first permanent centralized military medical service in 1899 , to helping to recruit medical officers during the Forces' recent mission in Afghanistan.

$\mathrm{He}$ also acknowledged the individual contributions of CMA members past and present. Since 1867, almost a third of the association's presidents have served in the military.

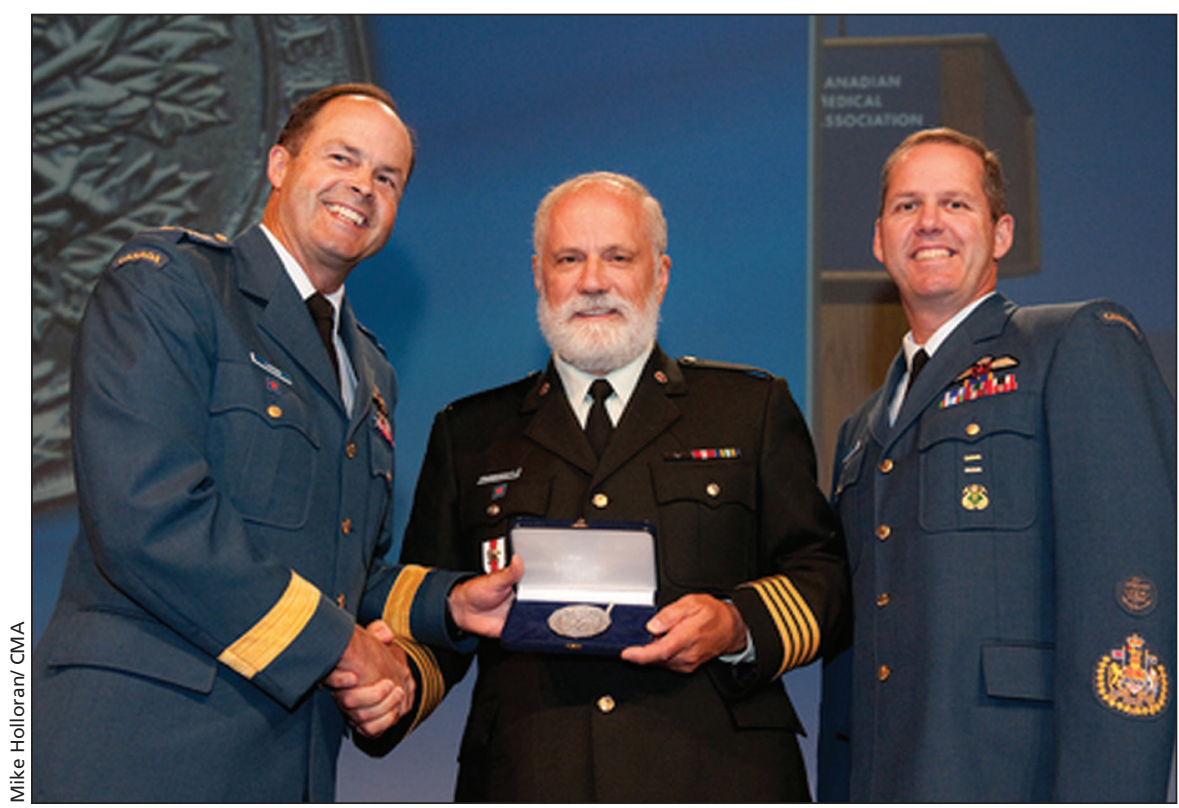

The Canadian Armed Forces awarded its top civilian honour to CMA.

In particular, "the commemoration of the First World War at general council this year is a meaningful reminder of the bond between the CMA and the Canadian Armed Forces," Lawson said.

As part of that commemoration, CMA awarded the inaugural John McCrae Memorial Medal on Aug. 20 to anesthesiologist Lt.-Col. Bethann Meunier of Kingston, Ontario. The new award recognizes exemplary service by current or former Canadian Forces clinical health services personnel.

CMA also contributed $\$ 10000$ to the Royal Regiment of Canadian Artillery toward the commission of two bronze statues of McCrae, who famously penned the war poem "In Flanders Fields."

A century on, McCrae's example continues to call out the best in physicians, said Surgeon General Brig.-Gen. Jean-Robert Bernier, accepting the donation. "His timeless poem has inspired generations ever since to reflect on the horrible costs and horrible tragedy of war, but it has equally inspired tremendous devotion to duty and self-sacrifice in the defence, protection and care for others." - Lauren Vogel, CMAJ

CMAJ 2014. DOI:10.1503/cmaj.109-4881 